\title{
Hydrological modelling for flood forecasting in Kénitra catchments, Western of Morocco
}

\author{
Mohammed Aghad ${ }^{1}$, Lhoussaine El Mezouary ${ }^{2}$, Mohamed Sadiki ${ }^{3}$ and Jamal Alkarkouri ${ }^{1}$ \\ ${ }^{1}$ Laboratory of environment, Societies and territories, Department of Geography, Faculty of Humanities and Social Sciences, \\ University Ibn Tofail, Campus Maamora, BP. 1331400 Kenitra, Morocco \\ ${ }^{2}$ Laboratory of hydroinformatics, Faculty of Sciences, University Ibn Tofail, Campus Maamora, BP. 1331400 Kenitra, Morocco. \\ ${ }^{3}$ Laboratory of Geoscience, Faculty of Sciences, University Ibn Tofail, Campus Maamora, BP. 1331400 Kenitra, Morocco.
}

\begin{abstract}
The Kenitra city located in western of Morocco. It is a port on the Sbu river, has a population in 2014 of 431,282 . This city has known a rapid growth in the number of inhabitants due to the migration of the surrounding villages, as well as the growth of a group of industrial activities, as this city is the third economic city in Morocco, as it contains the third industrial zone in Morocco, this region follows the activity of car factories. Given its social and economic importance, protecting it from flood risks is a priority for decision-makers. In this paper, we developed a hydrological model using HEC-HMS tools for the purpose of protecting human life and economic activities from the risk of floods. The forecast model has been used in order to identify and regions at risk from flooding and to take other precautions to protect life. Additionally, a forecast can provide the basis for preparing critical infrastructure for floods in order to minimize damage.
\end{abstract}

\section{Introduction}

The mathematical model in hydrology can then give a set of responses that can be submitted for observation as a representation of the phenomenon being examined. As a result, the model is a crucial instrument in the framework of scientific growth [1-5]; it can be used both inductively and deductively. The mathematical model, as an inductive tool, provides the representation and explanation of phenomena based on a collection of measurements [6-9]. The model permits theoretical experimentation with the system in many conditions as a logical tool since it identifies with the phenomenon researched [10-13].

Traditional flood management focuses on changing the features of a flood to lower peak elevations and spatial extents. Although flood risk is reduced by structural solutions (such as dams and embankments), it cannot be entirely eliminated. As a result, total flood protection is not always regarded as a practical option [14]. As seen in many countries, the cost and consequences of aging flood management infrastructure are significant.

As a result, experts [15] have advocated for a shift from structural flood protection to non-structural flood protection measures in flood-prone areas that are already occupied, such as land use management and flood forecasting, among other things. This paradigm change is inextricably linked to advances in atmospheric and earth surface instruments and remote sensing, as well as natural disaster predictions. Non-structural techniques are more reversible and less expensive than structural interventions for reducing flood risk[14]. At the global, continental, and basin scales, flood forecasting systems have been implemented. Plate
(2009) identified five distinct types of landscapes with distinct flooding patterns. Flood forecasting systems must be built and implemented differently in coastal areas where cyclones and storm surges are common causes of flooding. Flash floods, for example, are caused by high precipitation that is both spatially and temporally intensive, or by a quick release of water caused by dam breaches and lake outbursts. [16].

Various reviews have highlighted advancements in flood forecasting. The goal of this study is to provide a current, concise, and thorough examination of flood forecasting practices. Storm surge flooding sends a massive wave of water crashing against the coast. Realtime assimilation of precipitation data and forecasts is critical for flash flood forecasting[17].

Kenitra city part of the Sebou watershed, is potentially facing the risk of flooding which is increasingly recurrent and which is exacerbated by climate change and rapid urbanization. These risks generally cause heavy economic and social damage, often affecting vulnerable populations and territories (ABHS). This region is characterized annually by floods of different magnitudes from the Sebou River. These flood-prone areas are often populated and water overflows cause massive economic and human damage. With the strong urbanization experienced by the city of kenitra, the damage will be aggravated by the increased presence of the population and can cause human losses in the event of major floods.

The main physiographic and geomorphological characteristics of a studied watershed are of major importance because they intervene, and often in a combined way, in the modalities of surface flow. The physical characteristics of a watershed strongly 
influence its hydrological response, and in particular the flow regime during high or low water periods.

The delimitation of the Kenitra watershed, the calculation of its geometric (its area, its perimeter and its shape) and topographic properties, the orientation of the slopes and the altitude ranges, as well as the hydrographic network are extracted from a model. digital terrain (DEM).

The purpose of this study is flood modeling in the zone, the work makes it possible to deal with the risk of flooding, a hydrological study with the aim of intervening at different levels. Indeed, it allows the evaluation of structural measures which consist in the realization of the installations and works of protection against the floods. For this reason, the work utilized the HEC-HMS. HEC-HMS is a modeling platform allowing the combination of a multitude of sub-models allowing to describe different hydrological processes. These processes are direct surface runoff, soil infiltration, evapotranspiration, sub-surface and underground (groundwater) flows. For each of the processes that may be involved in the formation of floods at the outlet of a given watershed, it is therefore a matter of making a choice of model adapted to the specific runoff conditions of the area studied.

\section{Study areas}

The Kenitra city area is located on the Moroccan Atlantic coast $40 \mathrm{~km}$ north of the city of Rabat (figure 1). This study is interested in the development of a numerical model of the of runoff and hydraulic system of the downstream part of Oued Sebou. In fact, this part of the Sebou watershed has been classified as vulnerable to flooding (ABHS).

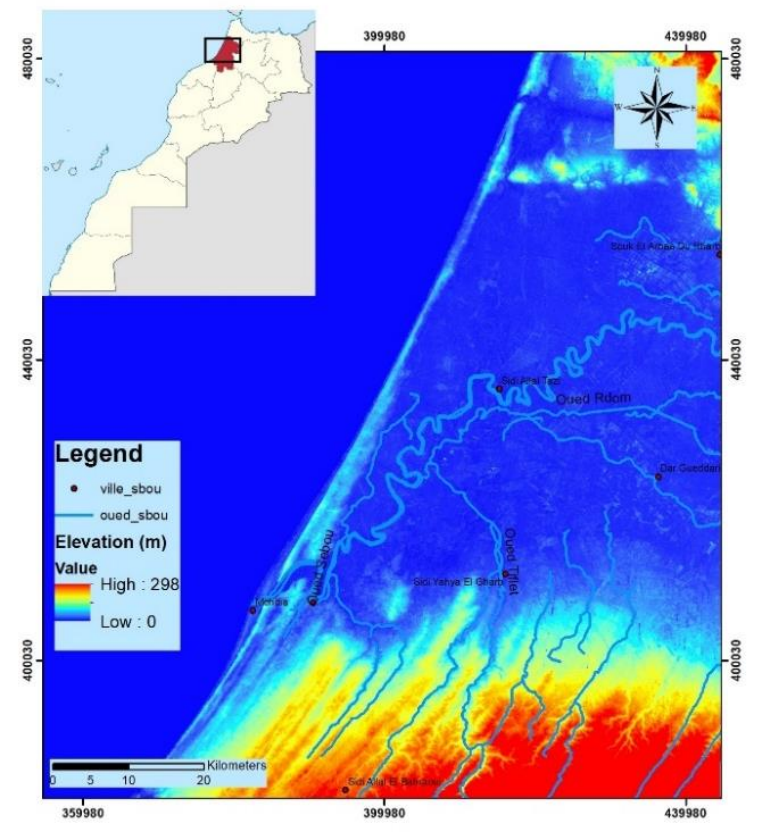

Fig. 1. DEM and geographic situation of Kenitra zone.

Climatological context, the area of Kenitra and its surroundings (kenitra-rabat-sale and sidi Sliman) is of the Atlantic-Mediterranean-type climate. Indeed, the analysis of the series of observations between 1980 and 2015 of precipitation, temperature indicate that the duration of the dry period is relatively long: on average, it varies from 5.6 to 6.6 months per year.

The extreme events to be reported concern the excessive rains in 1996 where Rabat-Salé, Kénitra and Sidi Slimane received respectively: $1163.6 \mathrm{~mm}, 1132.0$ and $849.1 \mathrm{~mm}$. In addition, the dry years were marked in 1994 for Rabat-Salé with a volume of $249.6 \mathrm{~mm}$ and in 2005 for Kénitra and Sidi Slimane who received respectively $291.4 \mathrm{~mm}$ and $191.4 \mathrm{~mm}$ (Figure 2).

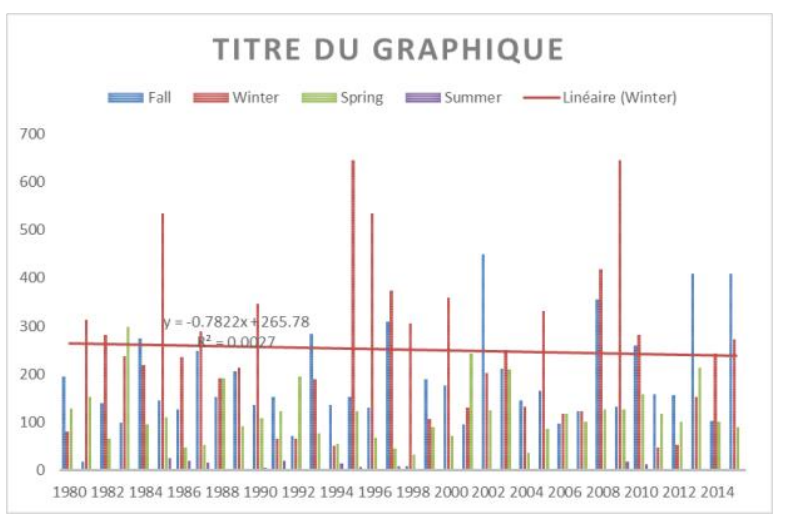

Fig. 2. Average precipitation from 1980 to 2015.

On the thermal level, the average absolute minima are of the order of 2.7 C noted in February 2012 in RabatSalé and Kénitra, and 1.8 C recorded in Sidi Slimane in 2005 , as for maximum temperatures absolute, the month of August 2010 was the hottest with temperatures of $31{ }^{\circ} \mathrm{C}, 31.3^{\circ} \mathrm{C}$ and $38.1^{\circ} \mathrm{C}$ recorded respectively in Rabat-Salé, Kénitra and Sidi Slimane.

The geology of the study area has attracted the attention of many researchers [18], [19]. The synthesis of the main results of this research shows that the substratum of the zone rests on marly formations which constitute the lower level of the water table. These layers are covered by a continental deposit from the Upper Villafranchian, called the red clay of the Maâmora, the thickness of which can reach in places about twenty meters. Sandy formations are deposited on these masses of clay, most of which come from oblique leaching of the red formations of the Maâmora [18]. These sandy deposits are from a few centimeters to more than 6 meters thick.

The soils of Maâmora have been the subject of an exhaustive study [20]. These soils are characterized by their relative homogeneity in the sense that they are mainly composed of sand of variable thickness (a few centimeters to more than $4 \mathrm{~m}$ ) which rest on a red and compact clay soil of Villafranchien, the variable thickness of which can reach very rarely $10 \mathrm{~m}$.

\section{Materials and Methods}

\subsection{Methodology}

In this paragraph, we will review the most important methodological and informational pillars that were 
employed in this study. In this context, we consider the following systematic division, first: we are using the DEM of the zone to delineating streams and watershed characteristics. In this level we have identified three points, that represent three outlets they are outlet of Ouad Sebou (Sebou outlet), and a second corresponds to the outlet of Sidi Boughaba (Sidi-Boughaba outlet), the third is the junction between Alfouarat stream and Sebou river (Alassam outlet), Figure 3, however, these points are exploited to create watersheds for each hydrographic segment between the hydrographic junctions. Second, we using the HMS tools to synthesize the numerical elevation model with the totality of the observed information in order to develop the hydrogeological simulation model.

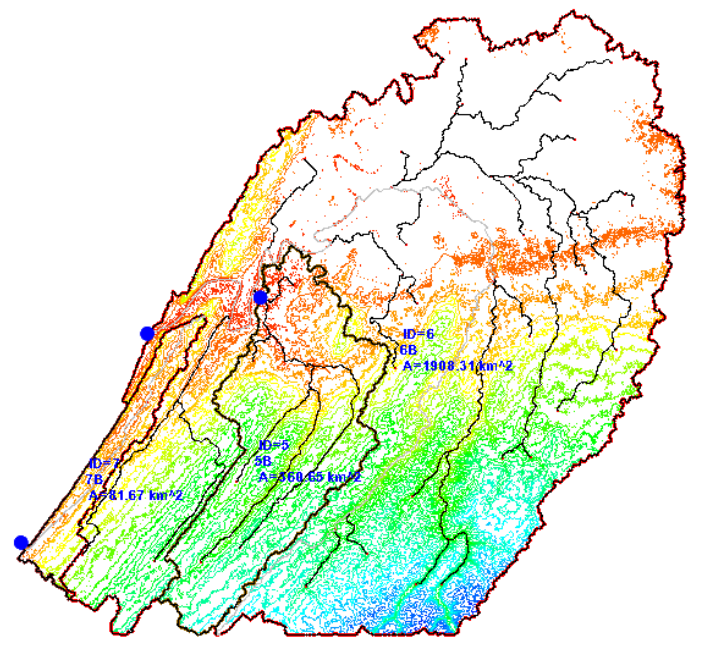

Fig. 3. Outlets located and watershed delineating.

The modeling process is primary has as objective the creation of the simulation files and can be completely done on the WMS software, the second part concerns the execution of the simulations from the files resulting from the part one, and this may be done entirely within the HEC-HMS software. So, the utility of the WMS platform during this study is to organize the simulation files, according to the steps shown in the figure 4.

From the raw DEM file, we'll proceed to a treatment to form it usable, then we establish the hydrographic network and therefore the delimitation of the watershed, and eventually we calculate the physical form parameters (surface, slope, ...) and hydrological parameters $(\mathrm{CN}, \mathrm{TC}, \mathrm{St}, \mathrm{Lag}, . .$.$) essential for the$ transfer function of the model.

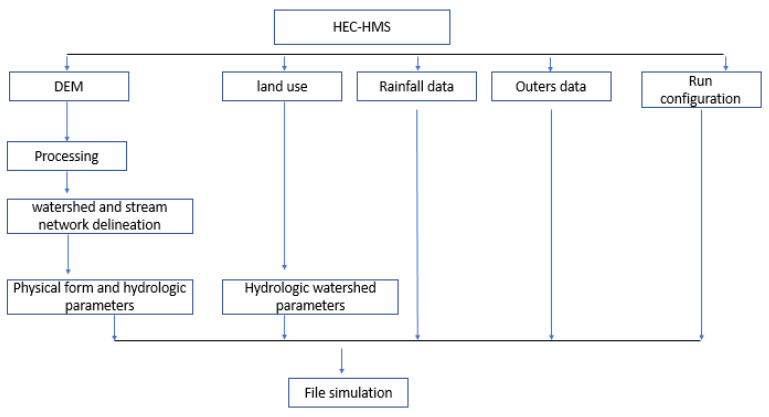

Fig. 4. model steps and methodology.

\subsection{Data processing}

The 30 meter Digital Elevation Model (DEM) of the zone area is provided by the U. S. Geological Survey (USGS). Digital Elevation Models (DEMs) are digital records of terrain elevations at regularly spaced intervals. The interval between elevations of 7.5-minute DEMs is 30-meters (Figure 1). DEMs can be used for creation of slope maps, aspect maps, shaded relief maps, and contour maps, for analysis of hydrography and runoff., The aera zone was clipped to produce accurate elevation data for calculations in hydrologic applications.

The step of pre-processing of terrain and hydrological basin by "HEC-HMS" is summarized first by linking on the digital elevation model "DEM" (Figure 1) for the study area. "HEC-HMS" analyzes the "DEM" and extracts the stream flow network and defines the subbasins, based on the physical representation of watersheds and rivers.

\subsection{Terrain pre-processing}

Terrain preprocessing marks the primary step in developing an HEC-HMS project. during this step, a terrain model is used as an input to derive eight additional datasets that collectively describe the drainage pattern of the watershed and allows for stream and subbasin delineation. the first five datasets are grid layers that represent the flow direction, flow accumulation, stream network, stream segmentation, and watershed delineation. the next two datasets are vector layers of the watersheds and streams. The last dataset, the aggregated watersheds, are employed primarily to boost the performance in watershed delineation (Figure 3).

Employing a program called TOPAZ, then WMS plots the hydrographic network. After the creation of the mouths, and therefore the delimitation of the 3 watersheds of Kenitra, Sidi Boughaba and Alfouarat. After delineating the watershed, WMS calculates all the physical parameters of the basin namely, area, perimeter, slope of the basin, length of the mainstream, maximum and minimum elevation, and other parameters.

WMS can calculate the compound curve number $(\mathrm{CN})$. Calculation of the curve number $(\mathrm{CN})$ is predicated on the SCS method, in fact, the SCS Runoff Curve Number method was introduced in 1954. This method makes it possible to estimate the volumes of runoff related to a rain event for a given watershed from the quantity of rainfall and certain physiographic characteristics (USDA-NRCS, 1986). The estimate of the runoff height from the SCS Method takes the subsequent form:

$$
\begin{aligned}
H_{r} & =\frac{\left(H_{p}-I_{a}\right)^{2}}{\left(H_{p}-I_{a}\right)+S_{r}} \text { When } H_{p}>I_{a} \\
H_{r} & =0 \text { When } H_{p}>H_{a}
\end{aligned}
$$

Where $H_{r}$ is that the peak of runoff $(\mathrm{mm}), H_{p}$ is that the peak of precipitation $(\mathrm{mm}), I_{a}$ is that the base retention (initial abstraction; $\mathrm{mm}$ ) and $S_{r}(\mathrm{~mm})$ is that the maximum potential retention on the watershed $(\mathrm{mm}) . S_{r}$ is set from the next metric system): 


$$
S_{r}=\frac{24400}{C N}-254
$$

Where CN is the Curve Number. In USDA-NRCS (1986 and 2004), the following empirical relationship is proposed between $I_{a}$ and $S_{r}$ :

$$
I_{a}=\lambda S_{r}
$$

Where $\lambda$ is that the initial abstraction coefficient ratio whose generally accepted value is 0.2 . The parameter $I_{a}$ represents all losses before the surface runoff itself begins, including water accumulated in surface depressions, intercepted by vegetation, evaporated and infiltrated before runoff (Jain et al., 2006). the worth of this parameter are often measured from observed precipitation and runoff data for small watersheds where water levels rise during rainy periods is rapid (USDANRCS, 2004).

In this step we use the subsequent altered DEM, to continue to the capacities that make the information supporting the delineation steps: Flow Direction Grid, Stream Grid, Catchment, and Adjoint Catchment.

\subsection{Model application and calibration}

The application of the HEC-HMS model simulation (Figure 5B) requires a database concerning the basin or the study area, so that the model can be applied. Among the essential data we can cite the morphometric characteristics of the basins (the surfaces of the subwatersheds, type of soil, plant cover) (Table 1), the meteorological characteristics (precipitation, evapotranspiration, control specification data, the initial date, The final date).

We exploit, flood events in April 2010 in the place of AlAssam for used on model testing. These data were obtained from ABHS (Sebou Hydraulic Basin Agency). The hydrograph of the centennial flood (Figure 5C) and for the cumulative voulm flood (Figure 5D) used is that of the observation data developed by ABHS.

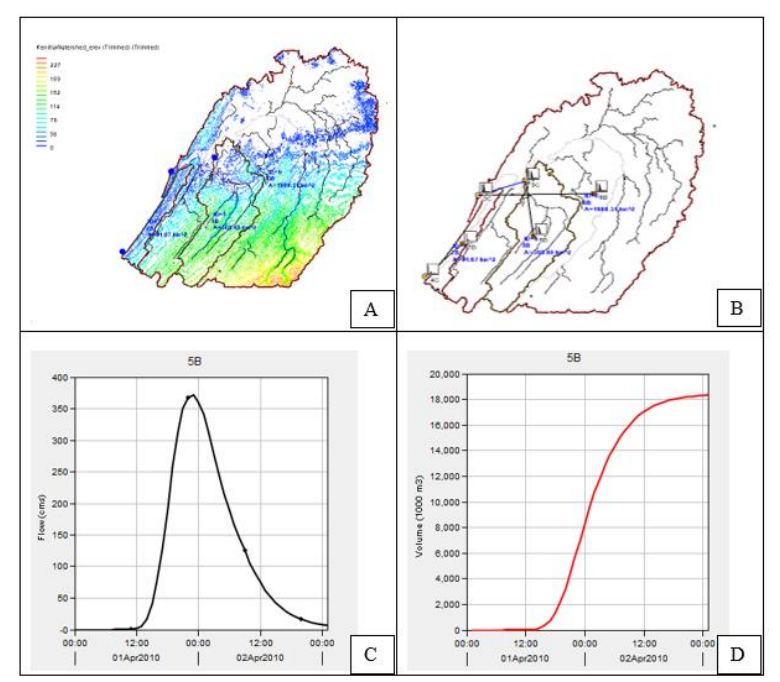

Fig. 5. Model design and processed results for Kénitra basin.

This hydrograph is taken at the entrance to Alfouarat. The establishment of the meteorological model relied on the various data related to precipitation and discharge that were observed during the period between 31 march and 1 april 2010, the next step is the stage of determining the pattern of the simulation time control specifications, these specifications mainly concern the informations of the start and the end date of simulation process, the time step, the model calibration method relied on comparing the computed results obtained by the numerical model and comparing them with the observed data.

To model infiltration loss, the SCS Curve Number Loss Model method was used. Thereover, The Curve Number (CN) model, developed by the Soil Conservation Service (SCS), calculates precipitation excess as a function of cumulative precipitation, soil cover, land use, and antecedent moisture using the equation:

$$
P_{e}=\frac{\left(P-I_{a}\right)^{2}}{\left(P-I_{a}\right)+S}
$$

where $P e$ is accumulated precipitation excess at time t; $P$ is accumulated rainfall depth at time $t ; I a$ is the initial abstraction (initial loss); and $S=$ potential maximum retention, a measure of the ability of a watershed to abstract and retain storm precipitation

The transformation of precipitation excess into direct surface runoff was modeled using the Soil Conservation Service unit hydrograph method (SCS). The baseflow was modeled using the exponential recession model. The reaches were modeled using the Muskingum routing model. Thereover, to route an inflow hydrograph, the Muskingum routing method employs a conservation of mass strategy. Most rivers have "looped" storage vs. outflow relationships, which the Muskingum approach can account for (i.e. hysteresis). As a result, this method can reproduce the widely observed enhanced channel storage on the rising side of a passing flood wave and decreased channel storage on the falling side.

The model was calibrated using the trial and error method, in which the hydrologist adjusts parameter values subjectively between simulations in order to find the minimum values of parameters that give the best fit between the observed and simulated hydrograph.

The determination coefficient DC was used as a criterion for evaluating the fit (Equation 6). 0.86 was the recession constant.

$$
D C=1-\frac{\sum_{i=1}^{n}\left[y_{c}(i)-y_{o}(i)\right]^{2}}{\sum_{i=1}^{n}\left[y_{o}(i)-\bar{y}_{o}\right]^{2}}
$$

Where $y_{o}(i)$ is the observed discharge for each time step $i, y_{c}(i)$ is the simulated value at time step $\bar{y}_{o}$ is the mean observed discharge, and $n$ is the total number of values within the time period. As previously stated, the flood event in the AlAssam Catchment in 2010 was used to calibrate the model.

\section{Results and discussion}

As stated in the introduction, each component of HECHMS simulates a different aspect of the precipitationrunoff process within a sub-basin of the basin. A set of parameters that specify the component's specific characteristics, as well as mathematical relationships that describe the physical processes, are required for component representation. The calibrated parameter values of each of the components represented in this model are shown in Table 1. 
Table 1. Calibrated parameter values.

\begin{tabular}{|c|c|c|c|c|c|c|c|}
\hline \multirow[t]{2}{*}{$\begin{array}{l}\text { Basin } \\
\text { Name }\end{array}$} & \multirow[t]{2}{*}{$\begin{array}{c}\text { SCS } \\
\text { Lag } \\
(\mathrm{min})\end{array}$} & \multirow[t]{2}{*}{$\begin{array}{l}\mathrm{Ar} \\
\text { ea }\end{array}$} & \multirow[t]{2}{*}{$\begin{array}{l}\mathrm{C} \\
\mathrm{N}\end{array}$} & \multicolumn{2}{|c|}{$\begin{array}{l}\text { Muskingu } \\
\mathrm{m} \\
\text { coefficient }\end{array}$} & \multirow{2}{*}{$\begin{array}{c}\text { Rec } \\
\text { essi } \\
\text { on } \\
\text { con } \\
\text { stan } \\
t\end{array}$} & \multirow[t]{2}{*}{$\begin{array}{l}\mathrm{D} \\
\mathrm{C}\end{array}$} \\
\hline & & & & $X$ & $\mathrm{~K}(\mathrm{~h})$ & & \\
\hline $\begin{array}{c}5 \mathrm{~B} \\
\text { (Alasam } \\
\text { basin) }\end{array}$ & 336.4 & $\begin{array}{l}36 \\
0 . \\
6\end{array}$ & $\begin{array}{l}8 \\
5\end{array}$ & 0.2 & 1 & 0.75 & $\begin{array}{l}0 . \\
9 \\
3\end{array}$ \\
\hline $\begin{array}{c}\text { 7B (Sidi } \\
\text { Boughaba } \\
\text { Basin) }\end{array}$ & 465.7 & $\begin{array}{l}81 \\
.6\end{array}$ & $\begin{array}{l}8 \\
5\end{array}$ & 0.2 & 1 & 0.71 & - \\
\hline $\begin{array}{c}\text { 6B (Sebou } \\
\text { Basin) }\end{array}$ & $\begin{array}{c}1022 . \\
9\end{array}$ & $\begin{array}{l}19 \\
08 \\
.3\end{array}$ & $\begin{array}{l}8 \\
5\end{array}$ & 0.2 & 1 & 0.75 & - \\
\hline
\end{tabular}

The Alassam catchment calibration and validation graphs are shown below. Figures 6 show that the observed and simulated graphs are in good agreement based on DC coefficient criteria (equation 6). Table 2 show the model calibration result for the ALassam catchment calibration.

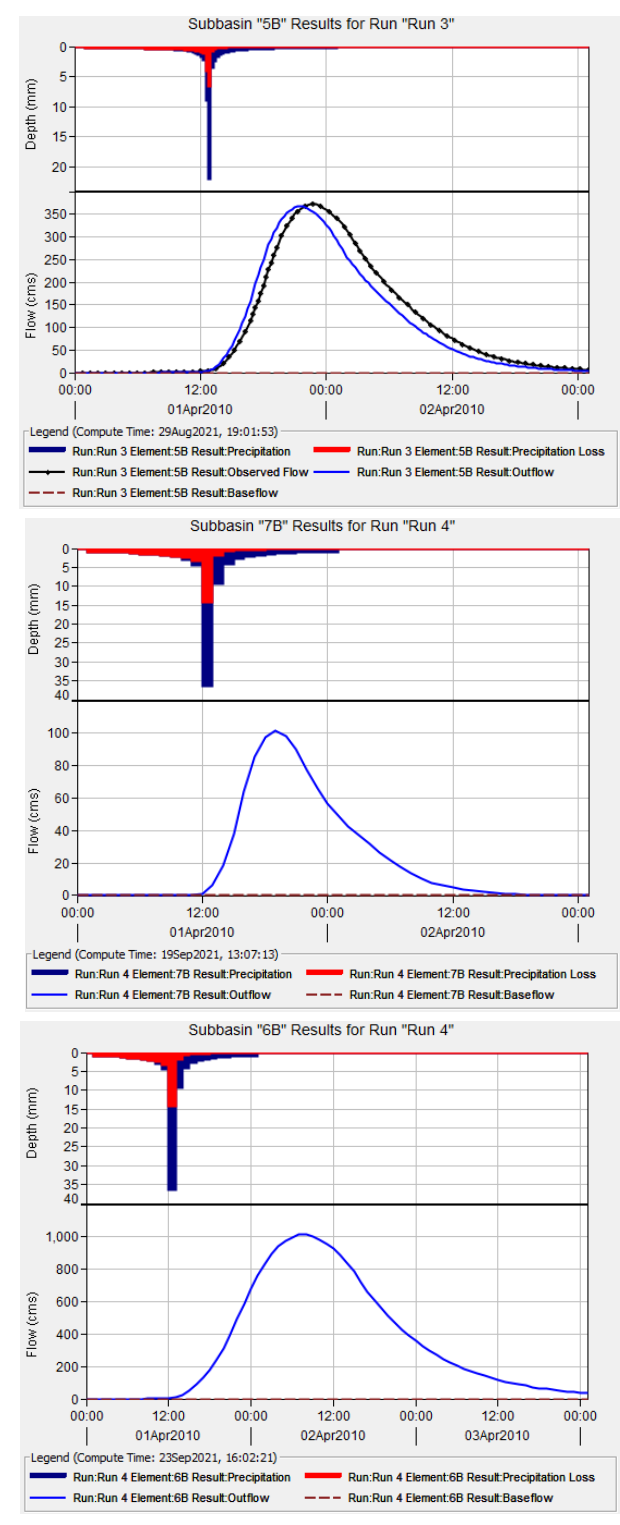

Fig. 6. A: Observed vs. simulated discharge for Alassam catchment; B and C: Simulated discharge for Sebou and SidiBoughaba catchments.

It very well may be found in the above charts that the calculated and musered peak releases happened around the same time, and their greatest time distinction was 60 minutes, which is satisfactory for flood guaging. The whole DC for the ALassam Catchment was above 0.93, while we applied the Alassam model to the Sbou Catchment and Sidi Boughaba Catchment with similar informational collection and got practically similar outcomes.

Table 2. Model calibration results.

\begin{tabular}{|c|c|c|c|c|}
\hline $\begin{array}{c}\text { Hydrolog } \\
\text { ic } \\
\text { element }\end{array}$ & $\begin{array}{c}\text { Drainage } \\
\text { Area } \\
(\mathrm{km} 2)\end{array}$ & $\begin{array}{c}\text { Peak } \\
\text { Dischar } \\
\text { ge } \\
(\mathrm{m} 3 / \mathrm{s})\end{array}$ & $\begin{array}{c}\text { Time of } \\
\text { Peak }\end{array}$ & $\begin{array}{c}\text { Volum } \\
\mathrm{e} \\
(\mathrm{mm})\end{array}$ \\
\hline $\begin{array}{c}\text { 5B } \\
\text { Alasam } \\
\text { basin) }\end{array}$ & 81.6710 & 101.9 & $\begin{array}{c}01 \text { Apr201 } \\
0,19: 00\end{array}$ & 47.83 \\
\hline $\begin{array}{c}\text { 7B (Sidi } \\
\text { Boughab } \\
\text { a Basin) }\end{array}$ & $\begin{array}{c}360.647 \\
2\end{array}$ & 369.7 & $\begin{array}{c}01 \mathrm{Apr} 201 \\
0,21: 00\end{array}$ & 49.70 \\
\hline $\begin{array}{c}\text { 6B } \\
\text { (Sebou } \\
\text { Basin) }\end{array}$ & $\begin{array}{c}1908.30 \\
97\end{array}$ & 1015.5 & $\begin{array}{c}02 \mathrm{Apr} 201 \\
0,08: 00\end{array}$ & 41.27 \\
\hline
\end{tabular}

\section{Conclusions}

It is clear from the results of this work that the modeling of the peak of the flood depends mainly on a set of information recorded and observed, therefore the accuracy of this modeling and the accuracy of the results obtained is mainly related to the accuracy and abundance of the recorded information. The results of the "AlAssam" basin showed that the model developed by "HEC-HMS" was able to re-simulate the flows and the level of the flood peak in the period in which we have the recorded information, but the lack of similar observed information for the two basins "Sebou" and "Sidi Bugaba" It makes the results of these two basins need more scrutiny and revision whenever this information becomes available.

\section{References}

1. Draoui, Y., et al., Quantification of Surface Water-Groundwater Exchanges by GIS Coupled with Experimental Gauging in an Alluvial Environment.

2. El Mansouri, B. and L.J.P.o.t.I.A.o.H.S. El Mezouary, Enhancement of groundwater potential by aquifer artificial recharge techniques: an adaptation to climate change. 2015. 366: p. 155-156.

3. El Mezouary, L., Modélisation mathématique et numérique des phénomènes d'écoulements et de transport de pollutions dans les milieux poreux: application a l'aquifère alluvial de la rivière de Magra, Italie. 2016.

4. Bader, D.C., et al., Climate models: an assessment of strengths and limitations. 2008. 
5. Forbes, C.T., L. Zangori, and C.V.J.J.o.R.i.S.T. Schwarz, Empirical validation of integrated learning performances for hydrologic phenomena: $3 \mathrm{rd}$ grade students' model-driven explanationconstruction. 2015. 52(7): p. 895-921.

6. El Mezouary, L., B. El Mansouri, and M. El Bouhaddioui. Groundwater forecasting using a numerical flow model coupled with machine learning model for synthetic time series. in Proceedings of the 4th Edition of International Conference on Geo-IT and Water Resources 2020, Geo-IT and Water Resources 2020. 2020.

7. El Mezouary, L., et al., Modélisation numérique de la variation saisonnière de la qualité des eaux souterraines de l'aquifère de Magra, Italie. 2015(2): p. 25-31.

8. El Mezouary, L., et al. Coupling of numerical flow model with the Susceptibility Index method (SI) to assess the groundwater vulnerability to pollution. in Proceedings of the 4th Edition of International Conference on Geo-IT and Water Resources 2020, Geo-IT and Water Resources 2020. 2020.

9. Kumar, P.J.W.R.R., Typology of hydrologic predictability. 2011. 47(3).

10. EL MEZOUARY, L., et al., Stochastic modeling of flow in porous media by Monte Carlo simulation of permeability. 2016. 15.

11. Sadiki, M.L., et al., Improvement of groundwater resources potential by artificial recharge technique: a case study of charf el Akab aquifer in the Tangier region, Morocco. 2019. 7(3): p. 224-236.

12. Blöschl, G. and M.J.H.p. Sivapalan, Scale issues in hydrological modelling: a review. 1995. 9(3-4): p. 251-290.

13. Toro, C.H.F., et al., A hybrid artificial intelligence model for river flow forecasting. 2013. 13(8): p. 3449-3458.

14. Tullos, D.J.J.o.e.m., Assessing the influence of environmental impact assessments on science and policy: an analysis of the Three Gorges Project. 2009. 90: p. S208-S223.

15. DiFrancesco, K.N. and D.D.J.J.J.o.t.A.W.R.A. Tullos, Flexibility in water resources management: review of concepts and development of assessment measures for flood management systems. 2014. 50(6): p. 1527-

1539.

16. Doswell III, C.A., et al., Flash flood forecasting: An ingredients-based methodology. 1996. 11(4): p. 560-581.

17. Madsen, H. and F.J.C.E. Jakobsen, Cyclone induced storm surge and flood forecasting in the northern Bay of Bengal. 2004. 51(4): p. 277-296.

18. De Beaucorps, G.J.A.R.F.R., Rapport Annuel, Evolution de l'humidité des sols dans une futaie claire de chêne-liège. 1956.
19. Thauvin, J.-P., Monographie hydrogéologique de la Mamora. 1966: Éditions de la Division de la Géologie.

20. Lepoutre, B. Régénération artificielle du chêne-liege et équilibre climacique de la subéraie en forêt de la Mamora. in Annales de la recherche forestière au Maroc. 1967. 